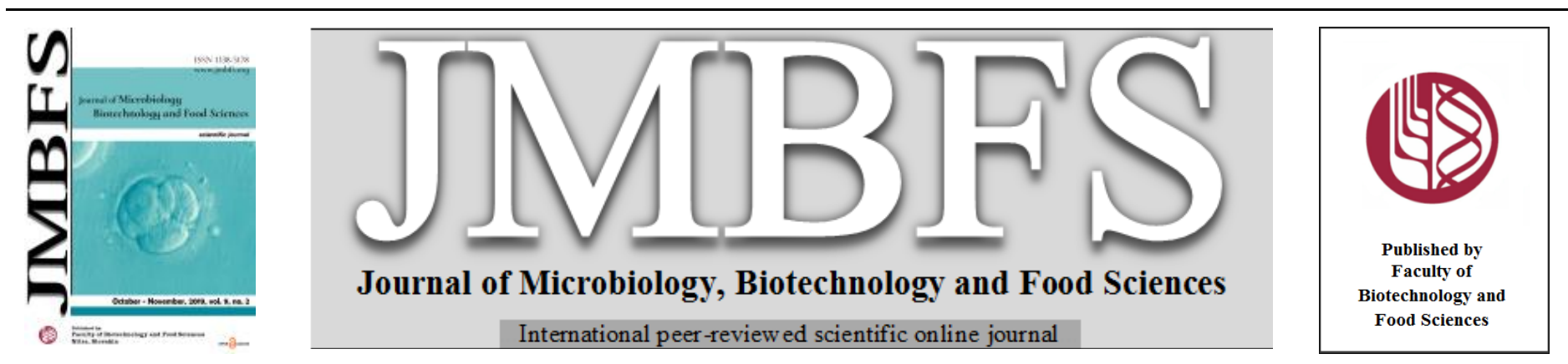

\title{
EVALUATION OF MONO-, DI- AND OLIGO-SACCHARIDES OF STAPLE INDIAN GRAIN FLOURS
}

\author{
Raman Manoharlal*, G.V.S. Saiprasad and K. Madhavakrishna
}

Address(es): Dr. Raman Manoharlal

ITC Limited, ITC Life Sciences and Technology Centre (LSTC), Peenya Industrial Area, $1^{\text {st }}$ Phase, Bengaluru-560058, Karnataka, India.

*Corresponding author: ramanpdf01@gmail.com

doi: $10.15414 / j m b f s .2020 .9 .4 .799-804$

ARTICLE INFO

Received 10.3.2018

Revised 14. 9. 2019

Accepted 25. 9. 2019

Published 3. 2. 2020

Regular article

open $\mathcal{O}$ access

\begin{abstract}
In this study, investigation of fourteen most common and traditionally used Indian staple grain flours: wheat, white rice, kutki rice, maize, maida, besan, sattu, little millet, quinoa, soybean, jowar, bajra, sooji and ragi was undertaken for the assessment of mono(namely glucose, fructose and galactose) and di- (namely sucrose) and oligo-saccharides (namely raffinose, stachyose and verbascose), with a special interest on the indigestible flatulence producing Raffinose Family Oligosaccharides (RFOs). The soluble saccharides were extracted with ethanol and evaluated by calorimetric and high-performance liquid chromatography (HPLC) methods. The results showed that among the investigated flours, total RFOs content on dry matter (DM) basis ranges from 0.07 (maize) to $12.61 \mathrm{mmol} / 100 \mathrm{~g}$ DM (chickpea). Within RFOs, raffinose was the major sugar (0.1 to $8.04 \mathrm{mmol} / 100 \mathrm{~g} \mathrm{DM}$ ), followed by stachyose (negligible to 6.3 $\mathrm{mmol} / 100 \mathrm{~g} \mathrm{DM}$ ) and verbascose (negligible to $0.14 \mathrm{mmol} / 100 \mathrm{~g} \mathrm{DM}$ ), except for soybean wherein the major RFO was stachyose. The observed sucrose content ranges from 0.05 (maize) to $6.32 \mathrm{mmol} / 100 \mathrm{~g} \mathrm{DM}$ (quinoa). Within mono-saccharides: glucose content ranges from negligible (chickpea, little millet, quinoa, pearl millet and sooji) to $3.64 \mathrm{mmol} / 100 \mathrm{~g} \mathrm{DM}$ (soybean), galactose content ranges from negligible (white rice, maize, sattu, quinoa, white millet, sooji and finger millet) to $1.72 \mathrm{mmol} / 100 \mathrm{~g}$ DM (chickpea) and fructose content ranges from negligible (chickpea, sattu, little millet, quinoa, soybean, sooji and finger millet) to $0.99 \mathrm{mmol} / 100 \mathrm{~g}$ DM (white rice). From the obtained results, the investigated grains can be classified as per the content of water soluble saccharides and accordingly a glycemic index and anti-flatulence chart can be prepared as a ready reference for dietary guidelines.
\end{abstract}

Keywords: Sugars, RFOs, Anti-nutritional factors and HPLC

\section{INTRODUCTION}

Being primary staples throughout the globe, grains constitutes a vital part of animal-feeds and human-foods providing $56 \%$ of the energy and $50 \%$ of the protein intake. A diverse array of grains are available for human consumption, either in raw- or processed-form, thereby constituting the largest component of recommended daily intake in all dietary guidelines (Flight and Clifton, 2006) The major grains include cereals: wheat, rice, maize and pulses with rye, oat, barley, triticale, sorghum and millet constitutes as minor grains. Across the world, the most commonly consumed grains are wheat, oat, rice, maize and rye with wheat constituting 66-75\% of total consumption (Slavin et al., 2000). In the last few decades, traditional Indian foods has been highly appreciated worldwide for their enriched organoleptic and nutritional properties. Grains also constitutes an important integral part of Indian food culture. Within India, different grains form staple diet of people from different part of the country. A combination of cereals-rice or wheat with grain legume is a popular daily diet across Indian states. Wheat and rice make up the most part of daily diet in North and South India, respectively. Contrary along with wheat and rice, jowar, bajra and corn to name a few, serves as integral part of meal in East and West India.

Because of their important role in most diets around the world, interest in the nutritive value of grain is increasing. Grains are a nutritionally rich product, delivering the recommended dietary nutrients and offers considerable health benefits including the reduced body weight gain, cardiovascular and diabetes risks (Jacobs Jr et al., 1998; Jacobs et al., 2007; Aune et al., 2013). Whole grains are recognized as an important source of sugars, calories and other trace nutrients like vitamins and minerals (Cleveland et al., 2000). Sugars are the functional food ingredients of grains contributing $\sim 60-70 \%$ of the total daily calories intake (Saxena, 2014). Flavour and nutritive values of grains are highly influenced by their sugar contents. Grain sugar have been associated with many health-promoting functions such as modulation of immune response, inhibition of cancer/tumour and stimulation of mineral absorption (Okarter and Liu, 2010). The major soluble sugar fraction of grains includes easily digestible mono(ribose, glucose, galactose and fructose), di- (maltose, sucrose) and indigestible raffinose family oligo-saccharides (RFOs; mainly raffinose, stachyose and verbascose) belonging to $\alpha$-D-galactosides group, wherein galactose is present in a $\alpha$-D-1,6-linkage. Raffinose is a tri-saccharide containing $\alpha$-D-(1-6) linked galactose to the glucose unit of sucrose; stachyose is a tetra-saccharide containing $\alpha$-D-(1-6) linked galactose to the terminal galactose unit of raffinose and verbascose is penta-saccharide containing a $\alpha$-D-(1-6) linked galactose to the terminal galactose unit of stachyose.

RFOs, the most interesting group among the soluble sugar fraction, belongs to low molecular-weight, heat resistant and non-reducing sugars. There is a great deal of interest in using RFOs as a functional foods ingredients (prebiotic) Physiologically, RFOs maintains the homeostasis of intestinal microflora (by promoting and inhibiting the growth of lactobacilli/bifidobacteria and enterobacteria, respectively), thereby contributing to human health in many ways (Gibson et al., 2004). However despites of these health benefits, RFOs belonging to a class of fibers called FODMAPs (Fermentable Oligo-, Di-, Monosaccharides And Polyols) are widely considered as anti-nutritional units mainly due to the lack of $\alpha$-galactosidase or melibiase ( $\alpha$-D-galactoside galactohydrolase, EC 3.2.1.22) in the gut of mono-gastric animals (Kotiguda $\boldsymbol{e}$ al., 2007). $\alpha$-galactosidase ( $\alpha$-GAL) hydrolyzes the terminal non-reducing $\alpha$-Dgalactose residues from the $\alpha$-D-galactosides, including galactose oligosaccharides (melibiose and RFOs) and branched polysaccharides [galactomannans and galacto-(gluco-) mannans] in an exo-fashion, thereby liberating the simple sugars (Naumoff, 2004). Being undigested, RFOs enters the large intestine, wherein they are fermented by native microbial flora and produce gases $\left(\mathrm{CO}_{2}, \mathrm{H}_{2}, \mathrm{H}_{2} \mathrm{~S}\right.$ and to a lesser extent $\left.\mathrm{CH}_{4}\right)$, resulting in the characteristic features of flatulence namely bloating, pain, nausea, cramps, diarrhoea, abdominal rumbling, social discomfort associated with the ejection of rectal gas and further worsen the symptoms of irritable bowel syndrome (IBS), a common digestive disorder (Cristofaro et al., 1974; Messina, 1999; Tsangalis and Shah, 2004). The severity of these flatulence symptoms varies from individual to individual depending upon their ethnic background, gastrointestinal microflora and amount of the food product ingested. These adverse effects of flatulence and poor digestibility can severely limit the utilization of grains for human consumption. 
Though extensive information is available on sucrose and oligo-saccharides in major legumes (Sosulski et al., 1982; Saini, 1989; Muehlbauer, 2002; Guillon and Champ, 2002; Sudar 2012), however the information available on antinutritional aspects of commonly used staple grains has not received due attention by food-chemists/nutritionists. Thereby, the following research was conducted 1 ) to select the simple extraction and suitable HPLC method to identify and quantify soluble saccharides and 2) to investigate the composition of soluble saccharides: glucose, galactose, fructose, sucrose, raffinose, stachyose and verbascose, with a special intention to identify the grain(s) with a relative low RFOs content Separate experiment was carried out to validate the soluble saccharides estimation by calorimetric method. A detailed and comparative insight of the soluble saccharides index of 14 raw whole grain flours (viz. wheat, white rice, kutki rice, maize, maida, besan, sattu, little millet, quinoa, soybean, jowar, bajra, sooji and ragi) commonly used in India, are provided here within. A comprehensive overview of aforementioned flours was described by Duyff (2012).

\section{MATERIAL AND METHODS}

\section{Chemicals}

Raffinose/Sucrose/D-Glucose assay kit (Catalog\#K-RAFGL) was procured from Megazyme International Ltd., Ireland (Wicklow, Ireland). HPLC-grade sugar standards: D-(+)-glucose (Catalog\#G8270), D-(+)-galactose (Catalog\#G0750), D-(-)-fructose (Catalog\#F0127), sucrose (Catalog\#S7903), D-(+)-raffinose (Catalog\#R0514), stachyose (Catalog\#S4001) and verbascose (Catalog\#56217) were procured from Sigma-Aldrich (Sigma Chemical Co., St. Louis, USA) Sugar-pak I chromatographic column, $10 \mu \mathrm{m}, 6.5 \times 300 \mathrm{~mm}$ (Part No WAT085188) was purchased from Waters Corporation (Waters India Pvt. Ltd.) Ethylenediaminetetraacetic acid calcium disodium salt (Catalog\#ED2SC) and other analytical reagents (AR) grade chemicals used in this study were obtained from Sigma-Aldrich (St. Louis, MO, USA).

\section{Seed materials and flour preparation}

The commercially available grain seeds/flours used in this study were purchased from the local market of Bengaluru, India. The dried seeds (moisture content $<7 \%$ ) were cleaned and sorted out thoroughly to make them free from dust, dirt, stubbles and foreign matter. Damaged, immature/broken with cracked hull and small-sized seeds were discarded mechanically so as to obtain clean seeds of uniform size. The cleaned seeds were milled to a fine powder using analytical grinder mill (CT 193 Cyclotec $^{\mathrm{TM}}$, FOSS India Pvt. Ltd., Mumbai) and passed through a $0.6 \mathrm{~mm}$ sieve to obtain flour of $500 \mu \mathrm{m}$ particle size. The obtained flours were stored as a fine powder in tightly closed containers at $4^{\circ} \mathrm{C}$ till further use.

\section{Soluble saccharides extraction and estimation}

Calorimetric. The soluble carbohydrate concentrations of grain flours were determined using an enzyme based Raffinose/Sucrose/D-Glucose assay kit (Megazyme) as per manufacturer's recommendation as described earlier (Kumar et al., 2010). It consists of $\alpha$-GAL (from Aspergillus niger), invertase (from yeast) and glucose determination reagent i.e. glucose oxidase peroxidase (GOPOD; glucose oxidase + peroxidase) for colorimetric estimation of sucrose and RFOs content. The kit is based upon the principle to stepwise hydrolyze complex soluble carbohydrates to glucose followed by its colorimetric measurement. Soluble sugars such as sucrose and RFOs were hydrolyzed with $\alpha$ GAL and invertase into D-glucose, D-galactose and D-fructose. D-glucose concentration was determined using GOPOD reagent. The concentration of raffinose, stachyose, verbascose and other higher homologues of the RFOs in flour samples were measured as a group, because $\alpha$-GAL hydrolyzes all members of the RFOs family. Since 1 mole of each of the RFOs contains 1 mole of D-glucose, the RFOs concentrations are presented on a molar basis. Briefly, finely ground flour $(0.5 \pm 0.01 \mathrm{~g})$ of each sample was treated with $95 \%$ ethanol (to digest the endogenous enzymes completely) at $85^{\circ} \mathrm{C}$ for $20 \mathrm{~min}$ and the final volume was made up to $50 \mathrm{ml}$ using sodium acetate buffer $(50 \mathrm{mM}, \mathrm{pH} 4.5)$. Digested mixture so obtained was incubated at the room temperature for $20 \mathrm{~min}$ and vortexed to obtain uniform slurry. Subsequently, $2 \mathrm{ml}$ of chloroform was added to $5 \mathrm{ml}$ of slurry obtained and vortexed for $15 \mathrm{~s}$ followed by centrifugation at $1000 \times \mathrm{g}$ for $10 \mathrm{~min}$. A volume of $0.2 \mathrm{ml}$ from the aqueous phase of the supernatant so obtained was taken in three tubes (namely, A, B, and C). A volume of $0.2 \mathrm{ml}$ of sodium acetate buffer $(50 \mathrm{mM}, \mathrm{pH} 4.5)$, invertase $0.2 \mathrm{ml}$ of invertase $(8.3 \mathrm{U} / \mathrm{ml})$ and a mixture of invertase $+\alpha$-GAL (invertase $8 \mathrm{U} / \mathrm{ml}$ and $\alpha$-GAL $40 \mathrm{U} / \mathrm{ml}$ ) was added into tubes A, B, and C, respectively. All three tubes were incubated at $50^{\circ} \mathrm{C}$ for $20 \mathrm{~min}$. Reagent blank $(0.4 \mathrm{ml}$ of sodium acetate buffer) and glucose control $(0.1 \mathrm{ml}$ of standard glucose solution, which contained $0.556 \mu \mathrm{mol}$ of glucose $+0.3 \mathrm{ml}$ of sodium acetate buffer) were also taken simultaneously. Subsequently, $3 \mathrm{ml}$ of GOPOD reagent was added in all of the tubes and incubated again at $50^{\circ} \mathrm{C}$ for $20 \mathrm{~min}$. The glucose concentrations for tubes $\mathrm{A}, \mathrm{B}$, and $\mathrm{C}$ and glucose control of was determined by measuring the change in absorbance of quinoneimine dye at $510 \mathrm{~nm}$ against the reagent blank using a UV/Vis Microplate and Cuvette spectrophotometer (Thermo Scientific ${ }^{\mathrm{TM}}$ Multiskan $^{\mathrm{TM}} \mathrm{GO}$ ). Glucose, sucrose and RFOs concentration are shown in $\mathrm{mmol} / 100 \mathrm{~g} \mathrm{DM}$.

The concentration of glucose, sucrose and RFOs was calculated as follows:

Glucose $(\mathrm{mmol} / 100 \mathrm{~g})=\Delta \mathrm{A} \times \mathrm{F} \times 50$

Sucrose $(\mathrm{mmol} / 100 \mathrm{~g})=(\Delta \mathrm{B}-\Delta \mathrm{A}) \times \mathrm{F} \times 50$

RFOs $(\mathrm{mmol} / 100 \mathrm{~g})=(\Delta \mathrm{C}-\Delta \mathrm{B}) \times \mathrm{F} \times 50$

where $\Delta \mathrm{A}, \Delta \mathrm{B}$ and $\Delta \mathrm{C}$ are the absorbance of sample plus sodium acetate buffer, sample plus invertase and sample plus invertase and $\alpha$-GAL enzyme solution, respectively.

$\mathrm{F}=$ Factor to convert from absorbance to $\mu \mathrm{mol}$ of glucose

0.556 ( $\mu \mathrm{mol}$ of glucose) / GOPOD absorbance for $0.556 \mu \mathrm{mol}$ of glucose

$250=$ conversion to $50 \mathrm{ml}$ of extract, $200=$ conversion from 0.5 to $100 \mathrm{~g}$ of sample and $1 / 1000=$ conversion from $\mu \mathrm{mol}$ to $\mathrm{mmol}$.

All enzymatic assays were performed in three technical replicates $(n=3)$ for each sample.

High Performance Liquid Chromatography (HPLC). Sample preparation. A method for quantitative extraction of soluble sugars from raw seed-flours and its subsequent recovery from the $80 \%(\mathrm{v} / \mathrm{v})$ ethanol solvent has been adopted as outlined earlier (Tahir et al. 2011; Gangola et al. 2014; Raja et al. 2015), with certain modifications. Approximately $150 \mathrm{mg}$ of grounded fine powdered flour of each sample was extracted twice with $40 \mathrm{ml}$ of $80 \%$ ethanol-water in a hot water bath at $55^{\circ}-60^{\circ} \mathrm{C}$ with a magnetic stirrer for $45 \mathrm{~min}$. The samples were centrifuged for $30 \mathrm{~min}$ at $10,000 \mathrm{rpm}$ and supernatant was collected. The extraction step was repeated and the recovered supernatants were pooled. The pooled extract was reduced in volume by using a rotary vacuum evaporator at $70^{\circ} \mathrm{C}$ to evaporate the ethanol. The concentrated sugar syrup was re-dissolved in $10 \mathrm{ml}$ of distilled water and filtered through a $0.45 \mu \mathrm{m}$ Millipore membrane (Millipore, Bedford, MA) into a $1.5 \mathrm{ml}$ HPLC vial with a rubber slit septum. The samples were then ready for injection into HPLC. HPLC conditions and Instrumentation. An HPLC system equipped with an auto-sampler, a gradient programmer, a solvent pump and a refractive index detector (Agilent 1200) was used. The chromatographic column used was a Waters sugar-pak I column (Part No. WAT085188) with an internal dimensions of $6.5 \times 300 \mathrm{~mm}$, filled with microparticulate size $(10 \mu \mathrm{m})$ of cation-exchange gel in calcium form. The mobile phase consists of $50 \mathrm{mg} / \mathrm{ml}$ solution of calcium disodium ethylenediaminetetraacetic acid ( $\left.\mathrm{CaNa}_{2} \mathrm{EDTA}\right)$. Operating conditions with a flow rate of $0.2 \mathrm{ml} / \mathrm{min}$ at an ambient temperature were maintained. Aliquots $(50 \mu \mathrm{l})$ of filtered samples were injected into the mobile phase of HPLC via an autosampler to record chromatograms. Detection was done by measuring the change in refractive index of the column effluent passing through the flow-cell. Al chromatograms were re-ordered on Agilent chemstation software. Authentic commercially available sugar standards: glucose, sucrose, raffinose, stachyose and verbascose were dissolved at $5 \mathrm{mg} / \mathrm{ml}$ in water, immediately prior to HPLC analysis and subjected to HPLC in a concentration range of $0-100 \mu \mathrm{g} / \mathrm{ml}$. A $50 \mu \mathrm{l}$ aliquots of these standard solutions were injected into the chromatographic system and the resulting peak areas were plotted against concentration for the linear calibration curve. Retention times of the standards were used to identify the corresponding peaks on the HPLC chromatograms of flour samples. Peak area was quantified by Chemstation software (Agilent). The relative concentration of individual sugar was calculated after superimposing the chromatogram of the sample on their corresponding standard curve. Individual sugar concentration was expressed as $\mathrm{mmol} / 100 \mathrm{~g}$ DM. Concentrations of raffinose, stachyose and verbascose were summed to compute total RFOs concentration.

\section{RESULTS AND DISCUSSION}

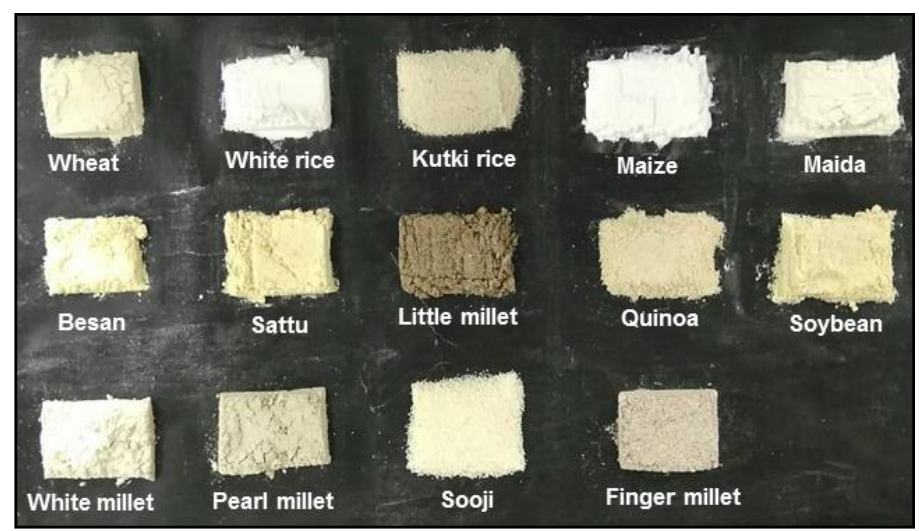

Figure $1 \mathrm{~A}$ pictorial presentation of various staple Indian grain flours used in this study. 
A.

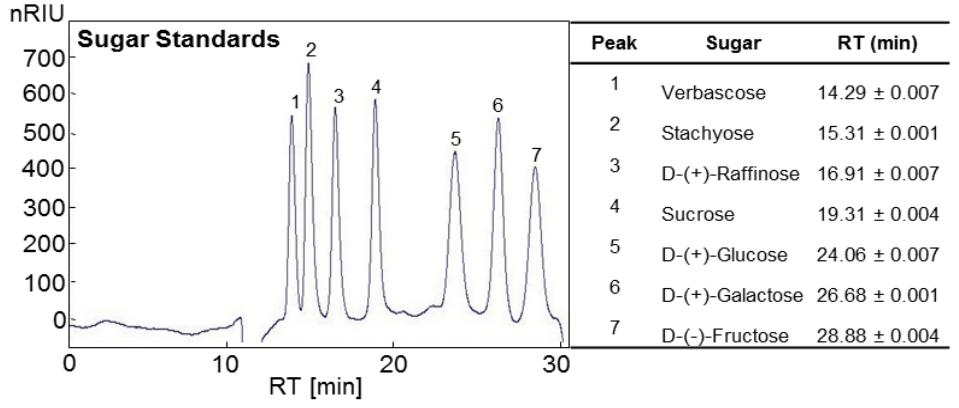

B.

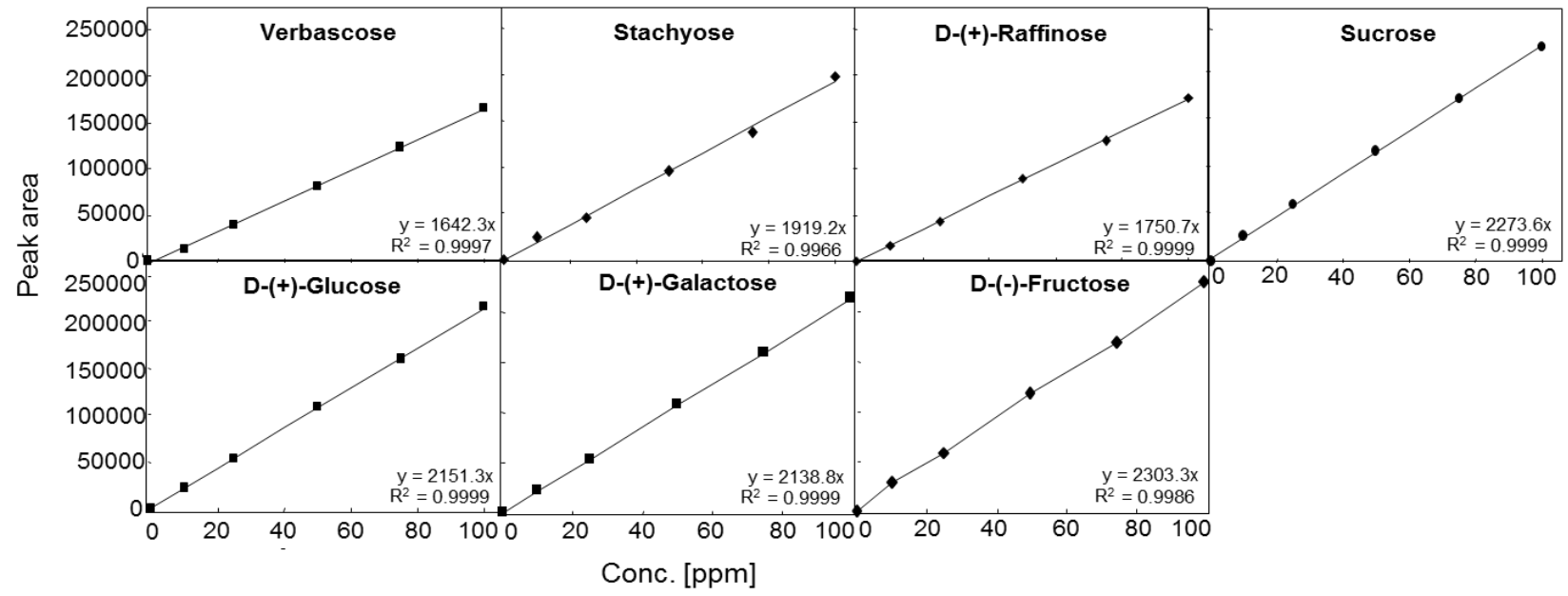

Figure 2 A typical chromatographic separation of sugar standards. A. Representative HPLC chromatograms illustrating the separation of sugar standards: glucose, galactose, fructose, sucrose, raffinose, stachyose and verbascose. Each sugar standard was evaluated by their peak area with corresponding retention times (in min): (1) Verbascose, $14.29 \pm 0.007$, (2) Stachyose, $15.31 \pm 0.001$, (3) Raffinose, $16.91 \pm 0.007$, (4) Sucrose, $19.31 \pm 0.004$ and (5) Glucose, 24.06 \pm 0.007 , (6) Galactose, 26.68 \pm 0.001 and (7) Fructose, $28.88 \pm 0.004$. B. Different concentration of each sugar standards $(0-100 \mathrm{ppm})$ was evaluated. Standard calibration graphs displaying the linearity between chromatogram peak area and amount of each standard sugar. The $\mathrm{R}^{2}$ values for the fitted lines displaying $>0.99$ indicates a good fit and gives confidence for reliable sugar estimation. Each data represent means \pm standard deviations (SDs) from triplicate measurements $(n=3)$.

As a first necessary step in the understanding of health effects or side effects per se of grains consumption, quantitative information to select the proper an diverse array of seed sources for physiological and biochemical investigations is needed. A list of 14 whole grains flours (Fig. 1) along with their subsequent foodproducts commonly used in India are mentioned in Table 1. The composition of water soluble saccharides of whole grain flours as determined by calorimetric method is shown in Table 2. Our results indicate that analysed grain flours harbours considerably variable amount of mono-, di- and oligo-saccharides. Notably, calorimetric method employed for total RFOs estimation does not quantify for raffinose, stachyose and verbascose as an individual component. Therefore, sugars evaluated by this method were expressed as mmol/100 g DM, instead of commonly expressed unit $(\mathrm{g} / 100 \mathrm{~g}$ DM) used for sugar estimation. Chromatographic methods allow the quantitation of individual sugars in a complex mixture. Thereby, investigated grain flours in this study were also subjected to HPLC for the separation and quantification of individual RFOs components. Representative HPLC chromatograms, retention time (in min) and linear equations obtained from the calibration curve of each standard sugar are shown in Fig. 2. In each case, a linear relationship between the sugar concentration $(0-100 \mathrm{ppm})$ and the observed peak area was obtained, with a determination coefficient $>99 \%$. The sugar profiling of each of flour sample analysed under the HPLC conditions described in materials and methods, are shown in Figure 2. Our result reveals the existence of at least nine peaks appearing between 10-30 min as minimum and maximum retention time that accounts to seven identified peaks with corresponding external standards. By comparison of the HPLC sugar profiling of each sample with the commercial available authentic standards, the following sugars have been identified and quantified: mono- (glucose, fructose and galactose), di- (sucrose) and oligosaccharides (raffinose, stachyose and verbascose). Our HPLC procedure (Fig. 3) is able to clearly resolve raffinose, stachyose and verbascose as an individual RFOs component along with sucrose, glucose, fructose and galactose. Table 2 exhibits the amount of soluble sugars calculated for each of flour sample analysed by HPLC method. Results are expressed in terms of mmol/100 g DM so that a comparison with calorimetric method could also be drawn. Notably, glucose, sucrose and total RFOs estimation by calorimetric and HPLC methods were largely in accord with each other, with a perfect positive correlation $(r=1)$ between these two methods.

Among all the grain flours examined, total RFOs content varied from 0.07 (maize) to $12.61 \mathrm{mmol} / 100 \mathrm{~g}$ DM (chickpea). Our results are also in well agreement with the previous observations, wherein RFOs are reported to be major sugar component in different varieties of legume seeds, accounting for the $31-76 \%$ of their total soluble sugars (Reddy et al., 1984). Within RFOs, a relative high level of raffinose was found in sattu $(8.04 \mathrm{mmol} / 100 \mathrm{~g} \mathrm{DM})$, followed by chickpea $(7.58 \mathrm{mmol} / 100 \mathrm{~g} \mathrm{DM})$ and soybean $(1.98 \mathrm{mmol} / 100 \mathrm{~g}$ $\mathrm{DM})$, with least in maize $(0.05 \mathrm{mmol} / 100 \mathrm{~g} \mathrm{DM})$. Interestingly among the cereal grains, a relatively high amount of raffinose was observed in whole wheat flour $(1.92 \mathrm{mmol} / 100 \mathrm{~g} \mathrm{DM})$. Notably the predominant RFO observed in all cases was of raffinose, except for soybean (wherein it was stachyose). Stachyose has been reported as main RFO in most legumes (Kuo et al., 1988; Saini, 1989; Guillon and Champ, 2002; Sudar 2012). Our results also demonstrated the highest content of stachyose in soybean $(6.3 \mathrm{mmol} / 100 \mathrm{~g} \mathrm{DM})$, followed by sattu $(3.91$ $\mathrm{mmol} / 100 \mathrm{~g} \mathrm{DM})$ and chickpea $(3.12 \mathrm{mmol} / 100 \mathrm{~g} \mathrm{DM})$ to almost negligible in cereal grains. Our results are also in well agreement with previous studies, wherein raffinose and stachyose were considered as major RFOs in seeds of gramineae and leguminosae family, respectively (Kuo et al., 1988). Like stachyose, verbascose amount also follows the similar trend, being highest in soybean $(0.14 \mathrm{mmol} / 100 \mathrm{~g} \mathrm{DM})$, followed by sattu $(0.08 \mathrm{mmol} / 100 \mathrm{~g} \mathrm{DM})$, chickpea $(0.05 \mathrm{mmol} / 100 \mathrm{~g} \mathrm{DM})$ to almost negligible in all the cereal grains examined. Sucrose, being the only di-saccharide and second most abundant water soluble saccharide, with highest content in quinoa $(6.32 \mathrm{mmol} / 100 \mathrm{~g} \mathrm{DM})$, followed by soybean $(4.16 \mathrm{mmol} / 100 \mathrm{~g} \mathrm{DM})$ and white millet $(2.64 \mathrm{mmol} / 100 \mathrm{~g}$ DM) to almost negligible in maize $(0.08 \mathrm{mmol} / 100 \mathrm{~g} \mathrm{DM})$ was observed. Our results showed comparatively wider variation in total RFOs (180-folds) than that of sucrose (126-folds) content. Within mono-saccharides: glucose content ranges from negligible (chickpea, little millet, quinoa, pearl millet and sooji) to 3.64 $\mathrm{mmol} / 100 \mathrm{~g} \mathrm{dm}$ (soybean), galactose content ranges from negligible (white rice, maize, sattu, quinoa, white millet, sooji and finger millet) to $1.72 \mathrm{mmol} / 100 \mathrm{~g}$ DM (chickpea) and fructose content ranges from negligible (chickpea, sattu, little millet, quinoa, soybean, sooji and finger millet) to $0.99 \mathrm{mmol} / 100 \mathrm{~g} \mathrm{DM}$ (white rice). Notably among all the cases, mono-saccharides were detected as minorities, except in case of sattu $(1.32 \mathrm{mmol} / 100 \mathrm{~g} \mathrm{DM})$ and soybean $(3.64 \mathrm{mmol} / 100 \mathrm{~g}$ $\mathrm{DM})$, where glucose has been observed in relative high levels. This fact agrees well with the previous studies (Phillips and Abbey, 1989), wherein low levels of mono-saccharides in grains are supposedly associated with their role as transitory intermediates for the synthesis of carbohydrates polymers. 

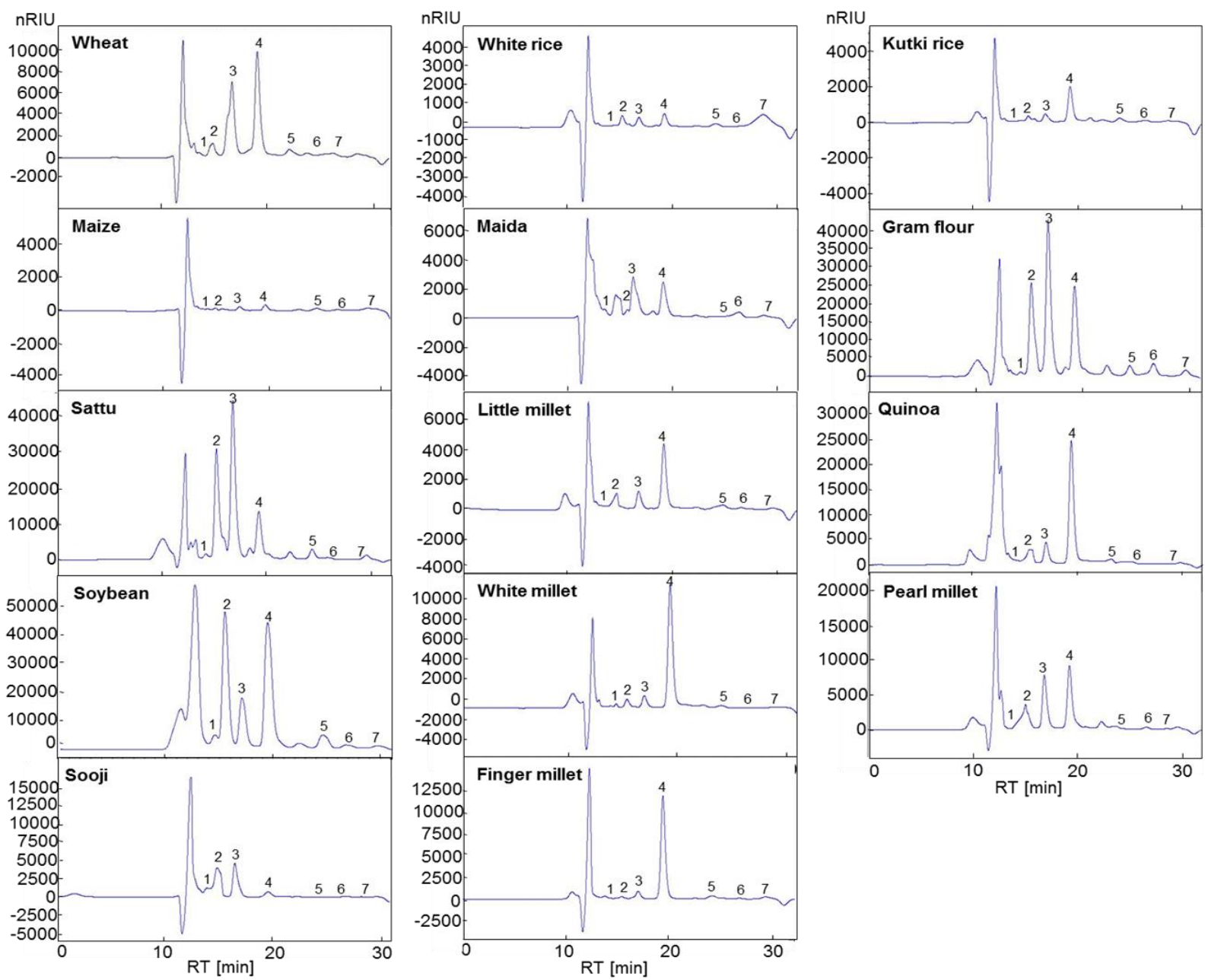

Figure 3 A typical chromatographic separation of ethanol soluble sugar extracts. Representative HPLC chromatograms showing the separation of ethanol soluble sugar extracts from various flours. The extracted saccharides peaks (glucose, galactose, fructose, sucrose, raffinose, stachyose and verbascose) were identified by comparison of their retention times with those of authentic standards. Peak area corresponding to each of sugar standard were quantified using external standard procedure. Data is expressed in terms of mmol/100 g DM. Each data represent means \pm standard deviations (SDs) from three independent measurements $(n=3)$.

Table 1 List of commonly used staple Indian grain flours

\begin{tabular}{|c|c|c|}
\hline Common / Local name & English / Scientific name & Food-products \\
\hline Gehun & Whole wheat flour (Triticum aestivum) & Roti/Chappati/Phulka, Parathas, Poori and Tortillas \\
\hline Chawal & White rice (Oryza sativa) & $\begin{array}{l}\text { Kozhakatai, Pooris, Rice bhakri/Rotis, Khichdi, Pulav/Biryani } \\
\text { and Kheer }\end{array}$ \\
\hline Kutki rice (Saamai/Sama) & Processed little millet & Bread, Roti, Dosa and Rice (substitute of staple rice) \\
\hline Makai/Makki & Maize (Zea mays) & Makki ki roti, Pudding, Thickener for soups, Stews and Sauces \\
\hline Besan & $\begin{array}{l}\text { Gram/Garbanzo bean/Chickpea } \\
\text { (Cicer arietinum) }\end{array}$ & $\begin{array}{l}\text { Pakoras/Fritters, Besan ladoos, Khandvi, Dhokla, Methi } \\
\text { muthia, Missi roti and Besan halwa }\end{array}$ \\
\hline Sattu & Toasted gram flour & $\begin{array}{l}\text { Sattu drink, Roti/Chappati/Phulka, Parathas, Poori, Laddu and } \\
\text { Chilla }\end{array}$ \\
\hline Kutki/Shavan & Little millet & Bread, Roti, Dosa and Rice (substitute of staple rice) \\
\hline Jowar & White millet (Sorghum vulgare) & Bhakris, Thepla, Thalipeeth and Flat bread \\
\hline Bajra & Pearl millet (Pennisetum glaucum) & $\begin{array}{l}\text { Bajra roti/Bajra bhakri, Thepla, Upma, Dosa, Idli, Vada, } \\
\text { Bajjis/Pakoras, Murrukus/Chakkli, Nipatlu, Pongal, } \\
\text { Mudda/Dumpling, Khichdi, Pulav/Biriyani, Kheer/Payasam, } \\
\text { baked products such as Flat bread and Biscuits or cooked just } \\
\text { like boiled rice }\end{array}$ \\
\hline Sooji/Rava/Rawa & Semolina/Cream of wheat & Savory, Sooji halwa, Rava dosa, Rava kesari and Rava upma \\
\hline Ragi/Nachni/Mandua & Finger millet (Eleusine coracana) & $\begin{array}{l}\text { Ragi dosa, Idli, Drinks, Puddlings, Dumplings, Roti, Upma, } \\
\text { Porridge, Mudde and Payasam }\end{array}$ \\
\hline
\end{tabular}

Despite of being involved in numerous physiological advantages to seeds/plants ranging from abiotic (Zuther et al., 2004; Peters and Keller, 2009) and biotic stresses (Kim et al., 2008), desiccation tolerance (Downie et al., 2003), antioxidant (Nishizawa et al., 2008; Nishizawa-Yokoi et al., 2008), transport and storage of carbon, signal transduction (Xue et al., 2007), mRNA export (Okada and Ye, 2009), membrane trafficking (Thole and Nielsen, 2008) and 
stabilization of photosystem II (Knaupp et al. 2011), the human consumption of food harbouring relative high levels of RFOs causes serious health implications related to indigestion and flatulence. Thereby, consumption of grains with a higher levels of digestible sucrose and low levels of RFOs are highly desirable. Among all the grains analysed, we observed that millets (little, white and finger millets) harbour most desirable combination of relative high sucrose and low
RFOs, which would be suitable for both food- and feed-purpose. Notably, wheat, sattu, quinoa, soybean and pearl millet also possesses relatively good amount of digestible sucrose, however their concomitant increased levels of total RFOs merits consideration before consumption.

\begin{tabular}{|c|c|c|c|c|c|c|c|c|c|}
\hline Sample & Method & Verbascose & Stachyose & Raffinose & ${ }^{*}$ Total RFOs & Sucrose & Glucose & Galactose & Fructose \\
\hline \multirow[t]{2}{*}{ Wheat } & Enzymatic & & & & $2.26 \pm 0.01$ & $2.87 \pm 0.35$ & $0.18 \pm 0.03$ & & \\
\hline & HPLC & $0 \pm 0$ & $0 \pm 0$ & $1.92 \pm 0.06$ & $1.92 \pm 0.06$ & $2.57 \pm 0.07$ & $0.12 \pm 0.01$ & $0.34 \pm 0.12$ & $0.11 \pm 0.01$ \\
\hline \multirow[t]{2}{*}{ White rice } & Enzymatic & & & & $0.23 \pm 0.07$ & $0.29 \pm 0.39$ & $0.2 \pm 0.02$ & & \\
\hline & HPLC & $0 \pm 0$ & $0.06 \pm 0$ & $0.11 \pm 0.01$ & $0.17 \pm 0.01$ & $0.16 \pm 0.01$ & $0.15 \pm 0.02$ & $0.01 \pm 0$ & $0.99 \pm 0.03$ \\
\hline \multirow[t]{2}{*}{ Kutki rice } & Enzymatic & & & & $0.18 \pm 0.04$ & $0.68 \pm 0.32$ & $0.18 \pm 0.03$ & & \\
\hline & HPLC & $0 \pm 0$ & $0.02 \pm 0$ & $0.1 \pm 0.01$ & $0.13 \pm 0.01$ & $0.49 \pm 0.02$ & $0.14 \pm 0.01$ & $0.09 \pm 0.01$ & $0.03 \pm 0.01$ \\
\hline \multirow[t]{2}{*}{ Maize } & Enzymatic & & & & $0.13 \pm 0.12$ & $0.05 \pm 0.36$ & $0.13 \pm 0.03$ & & \\
\hline & HPLC & $0.01 \pm 0$ & $0.01 \pm 0$ & $0.05 \pm 0$ & $0.07 \pm 0.01$ & $0.08 \pm 0.01$ & $0.1 \pm 0.01$ & $0 \pm 0$ & $0.04 \pm 0.01$ \\
\hline \multirow[t]{2}{*}{ Maida } & Enzymatic & & & & $0.75 \pm 0.07$ & $0.69 \pm 0.38$ & $0.05 \pm 0$ & & \\
\hline & HPLC & $0 \pm 0$ & $0 \pm 0$ & $0.64 \pm 0.02$ & $0.64 \pm 0.02$ & $0.65 \pm 0.02$ & $0.01 \pm 0$ & $0.32 \pm 0.01$ & $0.09 \pm 0.01$ \\
\hline \multirow[t]{2}{*}{ Gram flour } & Enzymatic & & & & $10.29 \pm 0.18$ & $0.44 \pm 0.36$ & $0.06 \pm 0$ & & \\
\hline & HPLC & $0.05 \pm 0.01$ & $3.12 \pm 0.07$ & $7.58 \pm 0.17$ & $10.75 \pm 0.24$ & $0.47 \pm 0.01$ & $0 \pm 0$ & $1.72 \pm 0.04$ & $0 \pm 0$ \\
\hline Sattu & Enzymatic & & & & $12.61 \pm 0.12$ & $2.63 \pm 0.29$ & $1.32 \pm 0.19$ & & \\
\hline \multirow[t]{2}{*}{ Little Millet } & Enzymatic & & & & $0.2 \pm 0.01$ & $1.44 \pm 0.36$ & $0.07 \pm 0.03$ & & \\
\hline & HPLC & $0 \pm 0$ & $0 \pm 0$ & $0.24 \pm 0.01$ & $0.24 \pm 0.01$ & $1.09 \pm 0$ & $0 \pm 0$ & $0.05 \pm 0.01$ & $0 \pm 0$ \\
\hline \multirow[t]{2}{*}{ Quinoa } & Enzymatic & & & & $1.42 \pm 0.03$ & $6.32 \pm 0.37$ & $0.06 \pm 0$ & & \\
\hline & HPLC & $0 \pm 0$ & $0.51 \pm 0.01$ & $0.87 \pm 0.05$ & $1.38 \pm 0.06$ & $6.1 \pm 0.19$ & $0 \pm 0$ & $0.03 \pm 0.01$ & $0 \pm 0$ \\
\hline \multirow[t]{2}{*}{ Soybean } & Enzymatic & & & & $8.95 \pm 0.04$ & $5.21 \pm 0.69$ & $3.64 \pm 0.54$ & & \\
\hline & HPLC & $0.14 \pm 0$ & $6.3 \pm 0.19$ & $1.98 \pm 1.43$ & $8.41 \pm 1.62$ & $4.16 \pm 0.13$ & $3.36 \pm 0.1$ & $0.33 \pm 0.01$ & $0 \pm 0$ \\
\hline \multirow[t]{2}{*}{ White millet } & Enzymatic & & & & $0.28 \pm 0.04$ & $3.23 \pm 0.31$ & $0.19 \pm 0.03$ & & \\
\hline & HPLC & $0.02 \pm 0$ & $0.09 \pm 0$ & $0.22 \pm 0$ & $0.32 \pm 0.01$ & $2.64 \pm 0.07$ & $0.14 \pm 0.03$ & $0.01 \pm 0.01$ & $0.02 \pm 0.01$ \\
\hline \multirow[t]{2}{*}{ Pearl millet } & Enzymatic & & & & $1.53 \pm 0.01$ & $2.29 \pm 0.34$ & $0.06 \pm 0.02$ & & \\
\hline & HPLC & $0 \pm 0$ & $0 \pm 0$ & $1.23 \pm 0.03$ & $1.23 \pm 0.03$ & $1.79 \pm 0.04$ & $0 \pm 0$ & $0.13 \pm 0.01$ & $0.02 \pm 0$ \\
\hline \multirow[t]{2}{*}{ Sooji } & Enzymatic & & & & $1.05 \pm 0.02$ & $0.69 \pm 0.41$ & $0.06 \pm 0$ & & \\
\hline & HPLC & $0 \pm 0$ & $0 \pm 0$ & $0.93 \pm 0.02$ & $0.93 \pm 0.02$ & $0.2 \pm 0.05$ & $0 \pm 0$ & $0 \pm 0$ & $0 \pm 0$ \\
\hline \multirow[t]{2}{*}{ Finger millet } & Enzymatic & & & & $0.12 \pm 0.02$ & $2.5 \pm 0.33$ & $0.21 \pm 0.03$ & & \\
\hline & HPLC & $0 \pm 0$ & $0.02 \pm 0$ & $0.15 \pm 0$ & $0.16 \pm 0$ & $2.09 \pm 0.05$ & $0.17 \pm 0.02$ & $0.04 \pm 0$ & $0 \pm 0$ \\
\hline
\end{tabular}

${ }^{*}$ Total RFOs were represented as the sum of raffinose, stachyose and verbascose.

Values $(\mathrm{mmol} / 100 \mathrm{~g})$ given are means \pm standard deviations (SDs) from three independent experiments $(n=3)$.

\section{CONCLUSION}

Nutritional security is a major priority in India. The world is vowed to end hunger by 2030 by sustainable food production. However apart from the increased productivity, the quality of food also needs to be improved so that their inherent nutritional properties can be tapped to a fuller extent. Our present study provide a comprehensive snapshot of the soluble saccharides of commonly used staple Indian grains, with an intension to reveal their unappreciated diversity in terms of anti-nutritional aspect (mainly RFOs). A reduction in the levels of flatulence-promoting RFOs at industrial level would aid in the development of value-added, nutritional and harmless feeds- and foods-products which will ensure better nutritional security. In this context, it is worth mentioning that conventional domestic and/ industrial processing methods (such as soaking, boiling, cooking, roasting, toasting, parching, frying, steaming, gamma radiation, ultrasonic, high hydrostatic pressure, fermentation, sprouting and supplementation of $\alpha$-galactosidase enzyme) has been adopted to reduce the RFOs levels to varying degree. However, so far none of aforementioned methods are commercially viable, which were time consuming, expensive, causing the loss of energy/minerals and also lack consumer acceptability. Scientific innovations in processing technologies to reduce the edible seeds RFOs content at industrial scale and/or social awareness about balanced and healthy food habits merit serious consideration.

Consequently, our data provides a baseline data of grains nutritional and antinutritional soluble saccharides, which needs to be considered by feed-and foodindustries in the formulation of corresponding feed- and food-products. The amount of RFOs and sucrose vary considerably in many common edible grains and this information will be useful to food-chemists and nutritionists. The results from the present investigation could also be extended to other agronomic important grains, thereby a complete inventory of soluble saccharides can be generated, which will further enhance our understanding of RFOs biosynthesis. A promising method for the industrial-scale purification of RFOs for use as prebiotics in functional foods as well as production of RFOs-free flours without compromising their nutritional benefits can be designed thereof. Our future studies are directed to achieve these goals.

Acknowledgments: We would like to acknowledge Dr. C.C. Lakshmanan [Head, Corporate R\&D, ITC Limited, ITC Life Sciences and Technology Centre (LSTC)] for his consistent support. Editorial and useful tips from In house manuscript committee of ITC-LSTC are well appreciated. Overall support from team Agrisciences, ITC-LSTC is greatly acknowledged.

\section{REFERENCES}

Aune, D., Norat, T., Romundstad, P. 1. \& Vatten, L. J. (2013). Whole grain and refined grain consumption and the risk of type 2 diabetes, a systematic review and dose-response meta-analysis of cohort studies. European journal of epidemiology, 28(11), 845-858. https://doi.org/10.1007/s10654-013-9852-5

Cleveland, L. E., Moshfegh, A. J., Albertson, A. M. \& Goldman, J. D. (2000) Dietary intake of whole grains. Journal of the American College of Nutrition, 19(sup3), 331S-338S. https://doi.org/10.1080/07315724.2000.10718969 Cristofaro, E., Mottu, F. \& Wuhrmann, J. (1974). Involvement of the raffinose family of oligosaccharides in flatulence. Sugars in Nutrition. HL Sipple \& KW McNutt, eds.

Downie, B., Gurusinghe, S., Dahal, P., Thacker, R. R., Snyder, J. C. \& Nonogaki, H. (2003). Expression of a GALACTINOL SYNTHASE gene in tomato seeds is up-regulated before maturation desiccation and again after imbibition whenever radicle protrusion is prevented. Plant Physiology, 131(3), 1347-1359. https://doi.org/10.1104/pp.016386

Duyff, R.L. (2012). Flour power: Learn about different kinds of flours https://foodandnutrition.org/summer-2012/flour-power-learn-different-kindsflours/

Flight, I. \& Clifton, P. (2006). Cereal grains and legumes in the prevention of coronary heart disease and stroke, a review of the literature. European journal of clinical nutrition, 60(10), 1145-1159. https://doi.org/10.1038/sj.ejen.1602435 
Gangola, M. P., Jaiswal, S., Khedikar, Y. P. \& Chibbar, R. N. (2014). A reliable and rapid method for soluble sugars and RFO analysis in chickpea using HPAEC-PAD and its comparison with HPLC-RI. Food Chemistry, 154, 127-133. https://doi.org/10.1016/j.foodchem.2013.12.085

Gibson, G. R., Probert, H. M., Van Loo, J., Rastall, R. A. \& Roberfroid, M. B. (2004). Dietary modulation of the human colonic microbiota, updating the concept of prebiotics. Nutrition research reviews, 17(02), 259-275. https://doi.org/10.1079/NRR200479

Guillon, F. \& Champ, M.-J. (2002). Carbohydrate fractions of legumes, uses in human nutrition and potential for health. British Journal of Nutrition, 88(S3), 293-306. https://doi.org/10.1079/BJN2002720

Jacobs, D. R., Andersen, L. F. \& Blomhoff, R. (2007). Whole-grain consumption is associated with a reduced risk of noncardiovascular, noncancer death attributed to inflammatory diseases in the Iowa Women's Health Study. The American journal of clinical nutrition, 85(6), 1606-1614. https://doi.org/10.1093/ajcn/85.6.1606

Jacobs Jr, D. R., Marquart, L., Slavin, J. \& Kushi, L. H. (1998). Whole-grain intake and cancer, An expanded review and meta-analysis. Nutrition and cancer, 30(2), 85-96. https://doi.org/10.1080/01635589809514647

Kim, M. S., Cho, S. M., Kang, E. Y., Im, Y. J., Hwangbo, H. \& Kim, Y. C. (2008). Galactinol is a signaling component of the induced systemic resistance caused by Pseudomonas chlororaphis O6 root colonization. Molecular plant microbe interactions, 21(12), 1643-1653. https://doi.org/10.1094/MPMI-21-121643

Knaupp, M., Mishra, K. B., Nedbal, L. \& Heyer, A. G. (2011). Evidence for a role of raffinose in stabilizing photosystem II during freeze-thaw cycles. Planta 234(3), 477-486. https://doi.org/10.1007/s00425-011-1413-0

Kotiguda, G., Kapnoor, S. S., Kulkarni, D. \& Mulimani, V. H. (2007) Degradation of raffinose oligosaccharides in soymilk by immobilized $\alpha$ galactosidase of Aspergillus oryzae. Journal of microbiology and biotechnology, 17(9), 1430

Kumar, V., Rani, A., Goyal, L., Dixit, A. K., Manjaya, J. \& Dev, J. (2010) Sucrose and raffinose family oligosaccharides (RFOs) in soybean seeds as influenced by genotype and growing location. Journal of Agricultural and Food Chemistry, 58(8), 5081-5085. https://doi.org/10.1021/jf903141s

Kuo, T. M., VanMiddlesworth, J. F. \& Wolf, W. J. (1988). Content of raffinose oligosaccharides and sucrose in various plant seeds. Journal of Agricultural and Food Chemistry, 36(1), 32-36. https://doi.org/10.1021/jf00079a008

Messina, M. J. (1999). Legumes and soybeans, overview of their nutritional profiles and health effects. The American journal of clinical nutrition, 70(3), 439s-450s. https://doi.org/10.1093/ajcn/70.3.439s

Muehlbauer, F. J. (2002). Carbohydrates in grain legume seeds, Improving nutritional quality and agronomic characteristics. Crop Science, 42(3), 979-981. https://doi.org/10.2135/cropsci2002.979a

Naumoff, D. G. (2004). Phylogenetic analysis of $\alpha$-galactosidases of the GH27 family. $\quad$ Molecular Biology, 38(3), 388-400. https://doi.org/10.1023/B:MBIL.0000032210.97006.de

Nishizawa-Yokoi, A., Yabuta, Y. \& Shigeoka, S. (2008). The contribution of carbohydrates including raffinose family oligosaccharides and sugar alcohols to protection of plant cells from oxidative damage. Plant signaling \& behavior, 3(11), 1016-1018. https://doi.org/10.4161/psb.6738

Nishizawa, A., Yabuta, Y. \& Shigeoka, S. (2008). Galactinol and raffinose constitute a novel function to protect plants from oxidative damage. Plant physiology, 147(3), 1251-1263. https://doi.org/10.1104/pp.108.122465

Okada, M. and Ye, K. (2009). Nuclear phosphoinositide signaling regulates messenger RNA export. RNA biology, 6(1), 12-16 https://doi.org/10.4161/rna.6.1.7439

Okarter, N. \& Liu, R. H. (2010). Health benefits of whole grain phytochemicals. Critical reviews in food science and nutrition, 50(3), 193-208. https://doi.org/10.1080/10408390802248734

Peters, S. \& Keller, F. (2009). Frost tolerance in excised leaves of the common bugle (Ajuga reptans L.) correlates positively with the concentrations of raffinose family oligosaccharides (RFOs). Plant, cell \& environment, 32(8), 1099-1107. https://doi.org/10.1111/j.1365-3040.2009.01991.x

Phillips, R. D. \& Abbey, B. W. (1989). Composition and flatulence-producing potential of commonly eaten Nigerian and American legumes. Food Chemistry, 33(4), 271-280. https://doi.org/10.1016/0308-8146(89)90037-X

Raja, R. B., Balraj, R., Agasimani, S., Dinakaran, E., Thiruvengadam, V. \& Kannan Bapu, J. R. (2015). Determination of oligosaccharide fraction in a worldwide germplasm collection of chickpea ('Cicer arietinum' L.) using high performance liquid chromatography. Australian Journal of Crop Science, 9(7), 605.

Reddy, N., Pierson, M., Sathe, S. \& Salunkhe, D. (1984). Chemical, nutritional and physiological aspects of dry bean carbohydrates-a review. Food Chemistry, 13(1), 25-68. https://doi.org/10.1016/0308-8146(84)90026-8

Saini, H. (1989). Legume seed oligosaccharides. Recent advances of research in antinutritional factors in legume seeds. Pudoc, Wageningen, 329-341.

Saxena, R. (2014). Bedside Obstetrics \& Gynecology, JP Medical Ltd. https://doi.org/10.5005/jp/books/12499
Slavin, J. L., Jacobs, D. \& Marquart, L. (2000). Grain processing and nutrition. Critical Reviews in Food Science and Nutrition, 40(4), 309-326. https://doi.org/10.1080/10408690091189176

Sosulski, F., Elkowicz, L. \& Reichert, R. (1982). Oligosaccharides in eleven legumes and their-classified protein and starch fractions. Journal of Food Science, 47(2), 498-502. https://doi.org/10.1111/j.1365-2621.1982.tb10111.x

Sudar, R. (2012). Oligosaccharides in legume Grains. Paper presented at the $6^{\text {th }}$ European Congress on Food.

Tahir, M., Lindeboom, N., Båga, M., Vandenberg, A. \& Chibbar, R. N. (2011). Composition and correlation between major seed constituents in selected lentil (Lens culinaris. Medik) genotypes. Canadian Journal of Plant Science, 91(5), 825-835. https://doi.org/10.4141/cjps2011-010

Thole, J. M. \& Nielsen, E. (2008). Phosphoinositides in plants, novel functions in membrane trafficking. Current opinion in plant biology, 11(6), 620-631. https://doi.org/10.1016/j.pbi.2008.10.010

Tsangalis, D. \& Shah, N. P. (2004). Metabolism of oligosaccharides and aldehydes and production of organic acids in soymilk by probiotic bifidobacteria International journal of food science \& technology, 39(5), 541-554. https://doi.org/10.1111/j.1365-2621.2004.00814.x

Xue, H., Chen, X. \& Li, G. (2007). Involvement of phospholipid signaling in plant growth and hormone effects. Current opinion in plant biology, 10(5), 483 489. https://doi.org/10.1016/j.pbi.2007.07.003

Zuther, E., Büchel, K., Hundertmark, M., Stitt, M., Hincha, D. K. \& Heyer, A. G. (2004). The role of raffinose in the cold acclimation response of Arabidopsis thaliana. FEBS letters, 576(1-2), 169-173. https://doi.org/10.1016/j.febslet.2004.09.006 